\title{
Google for education: estudo de caso na rede municipal de Salvador, Bahia
}

\section{Google for education: case study in the municipal school, Salvador, Bahia}

\author{
Tânia Maria Hetkowski \\ Doutora em Educação \\ Universidade do Estado da Bahia - UNEB \\ Salvador, Bahia - Brasil \\ hetk@uol.com.br \\ Taise Passos Cilindro \\ Mestra em Educação e Contemporaneidade \\ Universidade do Estado da Bahia - UNEB \\ Salvador, Bahia - Brasil \\ taisepassos2012@hotmail.com
}

\begin{abstract}
Resumo: Nas últimas décadas, grandes empresas de Tecnologias de Informação (TI), como a Google, passaram a desenvolver projetos Educacionais e estabelecer parceria com as redes públicas, privadas e organizações da sociedade civil, gerando preocupantes reflexões acerca das políticas públicas de acesso às tecnologias da informação e comunicação (TIC) no Brasil. Assim, o objetivo deste artigo busca discutir os propósitos do Google for Education e sua implementação, através do Projeto EscoLabs, nas escolas do Município de Salvador/BA. Com essa intenção, a abordagem metodológica do Estudo de Caso Descritivo, mediada pelos procedimentos de observação direta e entrevistas semiestruturada, permitiu a participação de professores, gestores e um servidor da Secretaria Municipal da Educação (SMED) na composição desta pesquisa. De modo que, os resultados obtidos nos conduzem a repensar sobre as políticas públicas de acesso às Tecnologias Digitais nas escolas das Redes Públicas e, sugerem alertas sobre a exposição de dados das instituições de ensino, dos professores e alunos às grandes corporações de TI.
\end{abstract}

Palavras chave: escolas da rede municipal; estudo de caso; google for education.

Abstract: In the last decades, large Information Technology (IT) companies, such as Google, began to develop Educational projects and establish partnerships with public networks, private and civil society organizations, generating worrying reflections on public policies for access to information and communication technologies (ICT) in Brazil. Thus, the objective of this article seeks to discuss the purposes of Google for Education and its implementation, through the EscoLabs project, in schools in the municipality of Salvador/BA. With this intention, the methodological approach of the Descriptive Case Study, mediated by the procedures of direct observation and semi-structured interviews, allowed the participation of teachers, managers, and public agents of the Municipal Department of Education (SMED) in the composition of this research. In such a way, the results obtained lead us to rethink public policies for access to Digital Technologies in schools of Public Networks and suggest alerts on the exposure of data from educational institutions, teachers, and students to large IT corporations.

Keywords: case study; google for education; municipal school.

Cite como

\section{(ABNT NBR 6023:2018)}

HETKOWSKI, Tânia Maria; CILINDRO, Taise Passos. Google for education: estudo de caso na rede municipal de Salvador, Bahia. Dialogia, São Paulo, n. 39, p. 1-16, e20621, set./dez. 2021. Disponível em: https:// doi.org/10.5585/39.2021.20621.

American Psychological Association (APA)

Hetkowski, T. M., \& Cilindro, T. P. (2021, set./dez.) Google for education: estudo de caso na rede municipal de Salvador, Bahia. Dialogia, São Paulo, 39, p. 1-16, e20621. https://doi.org/10.5585/39.2021.20621. 


\section{Introdução}

Entre o fim do Século XX e início do Século XXI, houve um crescimento vertiginoso de empresas de tecnologias de informação (TI), compreendidas como megacorporações ou holdings, com investimentos bilionários no desenvolvimento e incremento de tecnologias e de serviços, em especial pelas gigantes da Web, representadas pelo Google, Amazon, Facebook, Apple e Microsoft (GAFAM). Esse fenômeno se fez realidade em todo mundo $^{1}$, tal como a Espanha, Itália, México, Uruguai, Austrália, Brasil, entre outros países que aderiram aos serviços da GAFAM e se submeteram a uma conformidade tecnológica.

Esse cenário reverberou nos processos educacionais, afetando as redes de ensino público e privado, organizações da sociedade civil e, consequentemente, centenas e milhares de alunos e professores, de todas as idades. No Brasil, muitas Secretarias de Educação ${ }^{2}$ firmaram acordo com a empresa multinacional Google com objetivo de oferecer formação aos profissionais da educação e acesso às tecnologias digitais por parte dos alunos e comunidade escolar.

Não diferente das demais regiões, o Nordeste, neste caso o município de Salvador/BA, três escolas da Rede Pública Municipal formam o Projeto "Escolas Laboratório" (EscoLab), as quais se apresentaram à sociedade soteropolitana como parceiras do Google. Essa iniciativa provocou motivações, reflexões e questionamentos pela comunidade, suscitando um Estudo de Caso junto a Escola Laboratório Boca do Rio/Salvador/Ba, como campo empírico da pesquisa que compõe este escrito.

Esta provocação traz à baila discussões sobre políticas públicas de acesso e uso de tecnologias nos ambientes escolares e, a presença das corporações de TI nos processos de inclusão digital nos espaços escolares das redes públicas. Além disso, evocam tensões sobre a ética e privacidade dos dados de professores e alunos, incluindo as informações da instituição de ensino e do perfil desses sujeitos escolares, uma vez que esse monopólio, constantemente, é penalizado com denúncias ${ }^{3}$ e processos associados, geralmente, à violação de privacidade dos seus usuários.

Assim, intencionamos neste artigo compreender os propósitos do Google for Education e sua implementação, através das EscoLabs no Município de Salvador/BA, analisando o uso das

\footnotetext{
${ }^{1}$ https://edu.google.com/intl/ALL_br/latest-news/future-of-the-classroom/connecting-guardians-and-schools/ acesso 24 out. 2021

${ }^{2}$ Exemplos de alguns Estados e Municípios no Brasil que aderiram ao Google for Education.

http://www.amazonas.am.gov.br/2015/04/seduc-capacita-professores-para-uso-dos-aplicativos-google-educacao/ acesso 03 nov. 2019.

http://portal.educacao.rs.gov.br/Main/Noticia/Visualizar/portalseduc/Google-for-Education-1 acesso 03 nov. 2019.

http://www.sed.sc.gov.br/programas-e-projetos/16985-google-for-education acesso 03 nov. 2019

https://educacao.curitiba.pr.gov.br/noticias/google-education-disponivel-para-escolas-municipais/11931 acesso 03 nov. 2019.

https://www.educacao.sp.gov.br/noticias/google-na-educacao-conheca-a-nova-parceria-da-secretaria-com-a-gigante-da-tecnologia/acesso03 nov. 2019.

${ }^{3}$ https://www.tecmundo.com.br/mercado/143278-multada-europa-google-acusada-monopolio-na-india.htm acesso 20 jul. 2019.

https://noticias.r7.com/tecnologia-e-ciencia/google-e-processado-em-7-paises-por-violar-privacidade-de-usuarios-28112018 acesso 20 jul. 2019.
} 
ferramentas digitais nos processos educativos junto à comunidade escolar. Com esse intuito, realizamos um Estudo de Caso Descritivo, amparado por Entrevistas Semiestruturadas com professores e gestores da EscoLab Boca do Rio, incluindo a participação de um servidor da Secretaria Municipal de Educação (SMED) e, efetivando sistematicamente a Observação Direta junto à comunidade escolar.

Nesse sentido, o artigo tece, inicialmente, uma breve discussão sobre as políticas públicas educacionais, a influência da corporação de TI nesse processo e o atual cenário da cultura digital. Discussão que implica a compreensão sobre a forma como essas políticas são implementadas na escola e, por outro lado, a ausência de diálogos e planejamento com a comunidade escolar. Processo que gera reflexões potenciais sobre "produtos e serviços" nas escolas das redes públicas brasileiras.

Em seguida, a partir do Estudo do Caso, apresentamos a trajetória e os achados desta pesquisa, os quais demonstram a urgência de discussões sobre os desafios atuais da cibercultura dentro dos espaços escolares. Além disso, sinalizam que as grandes corporações de TIC, a partir do acesso aos dados da escola, colocam em risco a segurança digital de alunos, professores e gestão.

\section{Políticas públicas educacionais e a presença da corporação de ti}

Na década de 90, teóricos como Gentili (1998), Lehrer (1998), Frigotto e Ciavatta (2003), Hetkowski (2004) e Boneti (2006), provocaram e aprofundaram discussões acerca da influência da globalização e das interferências das organizações multilaterais na elaboração das políticas públicas, neste caso na Educação. E, da mesma forma, neste início do século XXI, vivenciamos a atuação das corporações de TI como um dos agentes importantes na definição de políticas educacionais no Brasil.

Nesse viés, compreendemos as políticas públicas como "o resultado da dinâmica do jogo de forças que se estabelecem no âmbito das relações de poder, constituídas por grupos econômicos, políticos, classes sociais e demais organizações da sociedade civil” (BONETI 2012, p. 27). O contexto da globalização gerou influências na reorganização da economia e na expansão das megacorporações, novos grupos de empresários surgiram e novas capacidades de intervenção na elaboração das políticas foram se solidificando.

O crescimento das corporações de TI, tais como Google, Amaz̧on, Facebook, Apple e Microsoft (GAFAM), no início do século XXI, ensejou o monopólio de grande parte da internet com exorbitantes faturamentos. Nesse sentido, em 2017, o Google se tornou a marca mais valiosa do

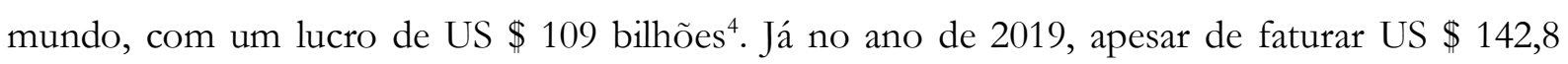

\footnotetext{
${ }^{4}$ https://brandfinance.com/images/upload/global_500_2017_locked_website.pdf acesso 18 jul. 2019.
} 
bilhões, a companhia ficou na terceira posição se comparada às concorrentes $A p p l e I\left(2^{\circ}\right.$ lugar com US $\$ 153,6$ bilhões) e Amaron que alcançou o topo com US $\$ 187,9$ bilhões ${ }^{5}$.

À medida que essas corporações crescem, sorrateiramente, seus produtos e serviços "invadem" a vida das pessoas, nas mais diversas áreas (trabalho, segurança, gestão, comunicação etc.). Sendo que na educação, o Google ganhou uma proporção mundial através da plataforma de aplicativos Google for Education, criados com o objetivo de uso e disseminação pelas escolas e universidades. De acordo com a companhia ${ }^{6}$, duas plataformas e um modelo de computador (programado para operar apenas com o sistema Chrome OS da Google) compõem o Google for Education, são eles: G Suite for Education; o Google Sala de Aula e os Chromebooks.

O G Suite for Education é uma ferramenta baseada em nuvem, composto pelo Gmail; Drive; Agenda; Documentos, Planilhas e Apresentações; Formulários; Jamboard; Sites; Hangoust Meet, Grupos e Vault. O Google Sala de Aula é uma plataforma digital, também em nuvem, que permite criar uma sala de aula online, reunindo alunos e professores e, os Chromebooks são notebooks com sistema operacional da própria empresa.

Dessa forma, as parcerias entre o Google e as instituições educacionais, para a oferta desses serviços e produtos, abrangem escolas, instituições e Universidades públicas e privadas do mundo todo. No Brasil (2019), verificamos que todas as regiões fecharam acordos entre as Secretarias de Educação com a empresa, em especial para uso na Educação Básica. Ou seja, a proporção das escolas nos Estados e Cidades que adotaram essas parcerias é significativa ${ }^{7}$ e carecem de estudos mais detalhados acerca dessa temática.

Nesse direcionamento, essas parcerias demostram uma problemática quando nos debruçamos para compreender os elementos que permeiam a homogeneização das políticas públicas educacionais no Brasil e a desconsideração das particularidades de cada região, estado, município, escola e proposta político-pedagógica de uma comunidade em formação. Essa tendência homogeneizadora é uma característica denunciada por Boneti,

\footnotetext{
${ }^{5}$ https://brandfinance.com/images/upload/global_500_2019_free.pdf acesso 23 out. 2019.

${ }^{6} \mathrm{https} / / /$ edu.google.com/intl/pt-BR_ALL/why-google/k-12-solutions/?modal_active=none acesso 02 fev. 2019.

${ }^{7}$ Exemplos de mais alguns Estados e Municípios que aderiram ao Google for Education

http://www.consed.org.br/central-de-conteudos/parceria-entre-secretaria-estadual-e-google-for-education-sera-expandida-para-municipiosdo-estado acesso 03 nov. 2019.

https://sedu.es.gov.br/Notícia/acoes-inovadoras-garantem-destaque-da-educacao-capixaba-no-google acesso 03 nov. 2019.

https://portaldtae.educacao.mg.gov.br/index.php/home/banco-de-noticias/25-primeira-oficina-do-gsuite-e-realizada-em-escola-de-belohorizonte acesso 03 nov. 2019.

http://institucional.educacao.ba.gov.br/noticias/governo-do-estado-lanca-projeto-e-nova-educacao-em-parceria-com-o-google acesso 03 nov. 2019.

https://gazetaweb.globo.com/portal/noticia/2019/07/pilar-e-o-1-municipio-de-al-a-implantar-sistema-de-tecnologia-na-rede-

municipal_81998.php acesso 03 nov. 2019.

https://www.pbagora.com.br/noticia/paraiba/governo-do-estado-cria-sala-de-aula-virtual-em-parceria-com-a-google-education/ acesso 03 nov. 2019.
} 
[...] a ação intervencionista das políticas públicas, parte do pressuposto de que há uma homogeneidade entre as pessoas, e/ou o objetivo desta ação é o da homogeneização, não tratando os grupos sociais considerados "diferentes" como tais, mas na perspectiva de os homogeneizar. É mesmo que dizer que existe um centro no qual as ideias dito científicas se encontram e dele nascem e impõem um padrão homogêneo a partir do qual devem se adaptar as singularidades. (2012, p. 23).

Podemos identificar essa afirmativa quando nos reportamos ao ano de 2016, ocasião em que o Magnífico Prefeito e o Excelentíssimo Secretário de Educação do Município de Salvador, realizaram uma visita à Sede do Google, na Califórnia, Estados Unidos da América (EUA) ${ }^{8}$, para conhecer a proposta do Google for Education, a qual passou a integrar o Projeto das Escolas Laboratório (EscoLabs) no Estado da Bahia. A primeira escola contemplada com esse Projeto foi inaugurada no mesmo ano; a segunda em 2017; e a terceira em 2018, totalizando três EscoLabs agregadas ao Google for Education.

As EscoLabs foram readequadas para atender o ensino básico em tempo integral, com funcionamento no contraturno das escolas regulares, ampliando a jornada escolar dos alunos do Ensino Fundamental da Rede Municipal de Salvador. Essa parceria com a Google, devido ao marketing massivo junto aos alunos, pais e comunidade, gerou narrativas de que as EscoLabs eram "escolas do Google".

Em entrevista", o então Prefeito afirmou que "esta parceria com o Google demonstra que estamos buscando o que há de mais moderno em tecnologia no mundo pra revolucionar a educação pública de Salvador". Declaração que corrobora com as discussões de Boneti (2012), quando reitera que, nessa conjuntura, o Estado busca por soluções prontas e acabadas que partem do centro às periferias, ou seja, adotam um padrão hegemônico para atender as necessidades dos setores mais pobres, a partir de parcerias e projetos criados por grupos dominantes.

Importante destacar que as três EscoLabs estão localizadas em espaços com histórico de abandono, ou seja, são bairros formandos a partir de sujeitos socialmente excluídos, com histórias de lutas por sobrevivência e carência por moradias. Atualmente, esses indivíduos convivem com insegurança e exclusão social e, onde também se encontra um público juvenil carente de recursos, vulneráveis às situações de violência, afastados de perspectivas de empregabilidade, descrentes da importância da educação em suas vidas e expostos ao trabalho infantil e condições de vidas precárias. Nesse sentido, há urgência de projetos construídos coletivamente com e para a comunidade e, jamais de propostas "importadas" de outra realidade muito diferente as demandas do Brasil.

\footnotetext{
${ }^{8}$ http://educacao3.salvador.ba.gov.br/prefeitura-e-google-discutem-detalhes-do-projeto-deeducacao-em-tempo-integral-em-salvador/ acesso 04 ago. 2019.

9 http://educacao3.salvador.ba.gov.br/prefeitura-e-google-discutem-detalhes-do-projeto-deeducacao-em-tempo-integral-em-salvador/ acesso 04 ago. 2019.
} 
Para Bonilla e Pretto (2000), Hetkowski e Dias (2019) os trâmites, como essas políticas e estratégias para a educação são planejadas e elaboradas pelos Estados e, implementadas pelas grandes corporações, ao longo dos anos, marcam a débil participação da sociedade civil, em especial dos educadores, nesse sistema verticalizado que ignora os principais atores que fazem a educação de um país.

Contudo, salientamos que o Google, como uma megapotência, vem enfrentando problemas na justiça por monopólios, por usar dados indevidamente e vulnerabilizar dados pessoais de seus usuários..$^{10}$ Esse fato, nos direciona pensar sobre a privacidade de dados de crianças e jovens, menores de idade, matriculados nessas escolas e expostos à subserviência, persuasão, consumismo e suscetibilidade de sua privacidade, a qual deveria ser garantida, a partir da letra da Constituição Federal (CF/1988) e do Estatuto da Crianças e de Adolescentes (ECA).

\section{Cultura digital na educação pública: oferta de serviços corporativos}

Com a Web $2.0^{11}$ e a criação dos Blogs, Wikis e Redes Sociais, as formas de se comunicar e interagir na internet ganharam novos formatos, conquistados a partir de ambientes colaborativos com possibilidades de criação de conteúdos, que podem ser produzidos pelos próprios usuários da rede internet. Ou seja, a cultura digital traz, em seu exórdio, dois lados: o primeiro enfatiza que os sujeitos, a partir das tecnologias digitais, se tornaram receptores passivos de conteúdo; por outro lado, essas tecnologias são potenciais na construção de uma inteligência coletiva (LÉVY, 2003), firmada na colaboração, nas redes digitais e ancorada pelos laços sociais, objetivando o compartilhamento de saberes e a produção de conhecimentos entre/pelos sujeitos, com respeito a diversidade e a singularidade das comunidades aprendentes.

Essas potencialidades, destacada pelo autor, mobilizam educadores e pesquisadores à urgência da escola interagir com tecnologias digitais, explorando suas possibilidades de alunos produzir conhecimentos, conhecer e aprender sobre outras culturas, acompanhar e experenciar uma nova linguagem, digital, para criar, reinventar e se comunicar com o mundo e seu entorno. Endossamos todas essas latências intrínsecas às tecnologias digitais, todas as possibilidades de exploração e de usos, mas precisamos, urgentemente, destacar que a cultura digital enfrenta um

\footnotetext{
${ }^{10}$ Os sites abaixo exemplificam alguns processos enfrentados pelo Google: https://www.conjur.com.br/2019-fev-07/ministerio-abre-processo-google-violacao-privacidade acesso 24 out. 2021 https://www.tecmundo.com.br/mercado/143278-multada-europa-google-acusada-monopolio-na-india.htm acesso 24 out. 2021 https://noticias.r7.com/tecnologia-e-ciencia/google-e-processado-em-7-paises-por-violar-privacidade-de-usuarios-28112018 acesso out. 2021 ${ }^{11}$ Termo utilizado para indicar um novo momento na internet do qual permitiu maior interação entre os internautas através dos sites de relacionamentos sociais, compartilhamento de vídeos, wikis, blogs, dentre outros serviços, possibilitando participação mais efetiva dos usuários.
} 
terceiro movimento, denominado capitalismo da vigilância, onde as grandes corporações ameaçam a segurança e a privacidade dos seus usuários, nesse caso crianças e adolescentes.

Para Hetkowski e Dias (2019), a Web, convergente com os fundamentos da inteligência artificial e da performance, em relação às informações que circulam em rede, deveriam agilizar o atendimento às demandas da sociedade. Porém, essa mesma performance, para Lemos (2019), exige cautela sobre a celeridade das mudanças nesse cenário digital, o qual está cada vez mais regido pela plataformização, dataficação e performatividade algorítmica (PDPA), caracterizando o Capitalismo da Vigilância nesta sociedade contemporânea.

A plataformização da sociedade, nesse sentido, diz respeito à crescente presença de plataformas digitais - geralmente produtos e serviços associados ao GAFAM, na mediação e realização da vida social. Essas mediações ocorrem, majoritariamente, através da ação de sistemas algorítmicos performativos que atuam na organização da vida social a partir do projeto das plataformas. (LEMOS e MARQUES, 2019, s/n).

Ou seja, cada ação nas plataformas gera inúmeros dados que, através do sistema de algoritmos potentes, torna-se possível dataficar, ou seja, transformá-los em código. De acordo com Saad (2019), quando os usuários nutrem compulsoriamente as plataformas GAFAM, com seus dados, elas se fortalecem a partir do momento que passam a conhecer os comportamentos, opiniões, consumos, escolhas e formas de relacionamentos dos seus usuários. (SAAD, 2019). Outrossim, corroboramos Zuboff (2015) ao afirmar que essa capacidade não pode ser compreendida apenas como um objeto ou uma capacidade tecnológica, mas como um fenômeno social que atinge a vida e a privacidade do sujeito, interferindo, inclusive, nos processos educacionais.

Nesse direcionamento, Dijck e Poell (2018) afirmam que as plataformas educacionais se tornaram um campo de interesses privados, corporativos e públicos em uma economia online. $\mathrm{Na}$ medida que uma grande quantidade de dados é gerada diariamente, através dessas plataformas disponíveis nas escolas, megaempresas de TI coletam informações dos estudantes, potenciais "massa" de consumidores dos seus produtos.

[...] As plataformas de mídia social são impulsionadas por um número limitado de modelos de negócios que se baseiam principalmente em dados como alavanca conectiva para gerar valor econômico. A mercantilização no contexto de plataformas educacionais geralmente envolve o processamento de dados de aprendizado que tornam os fluxos da big data monetizáveis e potencialmente lucrativos. (DIJCK; POELL, 2018, p.3, tradução nossa).

Esse contexto está suscitando preocupações, entre pesquisadores e educadores, acerca da proteção de dados dos sujeitos escolares e das informações que circulam nas instituições de ensino, 
em especial pela falta de transparência nos contratos efetivados entre essas corporações e as redes de ensino. Esses foram alguns dos questionamentos apontados por Kanashiro (2016), em relação ao acordo feito entre o Google e a Universidade Estadual de Campinas (Unicamp), no qual revela a ausência de debates com a comunidade e um desestímulo aos projetos já existentes na universidade, como o Teleduc ${ }^{12}$, desenvolvido pela instituição e o Moodle ${ }^{13}$, ambos softwares livres.

Quando refletimos sobre o universo infanto-juvenil, esses fatores mostram mais preocupantes por ser tratar de menores e descumprem o artigo 98, inciso I, do ECA, que preceitua sobre as medidas de proteção como direitos reconhecidos, os quais não podem ser "ameaçados ou violados: I - por ação ou omissão da sociedade ou do Estado" (ECA, 1990). Salientamos a importância das discussões nas instituições de ensino, o papel do Estado na garantia dos direitos dos sujeitos escolares e, sobretudo, as violações pelo capitalismo da vigilância, dessas grandes corporações, junto às crianças e adolescentes nos espaços da escola.

Elas vão atuar dentro da escola do mesmo modo que atuam fora, ou seja, orientadas por interesses comerciais. São corporações ligadas ao Norte Global, que não têm nenhuma relação com as políticas educacionais brasileiras e não compartilham as preocupações de proteção à infância e a adolescência no Brasil. (VENTURINI, 2019, s/n.).

As plataformas privadas se estruturam, na educação, amparadas por:

um modelo único de negócios customizado para era digital em que a matéria prima principal são os dados, capturados e extraídos pelas empresas detentoras e que, assim, se estabelecem como intermediários entre usuários, anunciantes, instituições de ensino e governos". (JUNQUEIRA, 2019, s/n).

Assim, as tecnologias digitais na educação, enfrentam grandes desafios diante da oferta dos serviços corporativos pois, conforme Lemos (2019), a PDPA e os monopólios das GAFAM colocam em xeque as ideias de emancipação, liberdade e autonomia que originaram a cultura digital, baseada nos laços sociais e na produção de saberes, importantes para as Redes Públicas de Ensino deste país.

12 O TelEduc é um sistema de aprendizado eletrônico, livre e gratuito. Possui um conjunto de ferramentas como agenda, chat etc.

13 O Moodle é um sistema de código aberto, conhecida como Ambiente Virtual de Aprendizagem (AVA), funciona como uma sala de aula online onde professores podem disponibilizar material didático e propor tarefas interativas 


\section{Caminhos metodológicos}

Como abordagem metodológica desta pesquisa, considerando a essencialidade de uma descrição detalhada sobre a trajetória percorrida e as tomadas de decisões ao longo do estudo, optamos pelo Estudo de Caso fundamentado em Yin (2001, p.32), que o compreende como "uma investigação empírica que investiga um fenômeno contemporâneo dentro do seu contexto da vida real, especialmente quando os limites entre o fenômeno e o contexto da vida real não estão claramente definidos".

Assim, compreendemos que o Google nos espaços educacionais, as políticas educacionais no Brasil aderindo aos serviços e plataformas corporativas, o Big Data e a ameaça da privacidade dos dados dos usuários, são entendidos como fenômenos contemporâneos. Nesse sentido, a EscoLab Boca do Rio representa o contexto da vida real, em que o Google for Educacion se presentificou junto aos alunos e professores.

Considerando que o município de Salvador/Ba, concentra as três EscoLabs, elegemos a EscoLab Boca do Rio ${ }^{14}$ como campo empírico. Na primeira escola, denominada EscoLab Coutos ${ }^{15}$, verificamos que a comunidade escolar não aderiu aos serviços da megacorporação; na EscoLab 360, também localizada no bairro Coutos, havia uma recente implantação do projeto, assim optamos pela EscoLab Boca do Rio, por ser a única que, no momento, estava aderindo ao Google for Education.

Quanto aos sujeitos da pesquisa, intencionamos escutar seus posicionamentos a partir das funções desempenhadas na escolha, bem como inerentes à disponibilidade em colaborar com esse estudo. Assim, nove professores, dois gestores e um funcionário da Secretaria Municipal da Educação do Salvador (SMED) foram nossos partícipes, integrantes e sujeitos escolares que colaboraram, enormemente, com esclarecimentos e achados oportunos para esta investigação.

Os instrumentos utilizados, nesta pesquisa, foram Entrevistas Semiestruturadas e Observação Direta no lócus da pesquisa, acompanhadas de um Diário de Bordo. Destacamos que as observações foram efetivadas durante trinta dias (idas ao campo), três dias vezes por semana em turnos alternados (manhã e tarde), totalizando 100 horas de estudo in loco. A investigação passou por todos os procedimentos exigidos pelo Comitê de Ética em Pesquisa.

As Entrevistas Semiestruturadas ${ }^{16}$ foram planejadas a partir de dois roteiros: o primeiro destinado aos professores e gestores (com oito perguntas) e, o segundo direcionado ao funcionário

\footnotetext{
${ }^{14}$ A escola tem esse nome por estar localizada em um bairro de Salvador chamado Boca do Rio.

${ }^{15}$ O bairro Coutos está localizado no Subúrbio de Salvador/Ba, compreendido como Cidade Baixa.

${ }^{16}$ Os partícipes assinaram o Termo de Consentimento Livre e Esclarecido (TCLE), preservando o anonimato e com permissão de codin omes, sendo os mesmos representados por cantores baianos.
} 
da SMED (com seis perguntas), ambos contemplando perguntas objetivas e abertas sobre a parceria, implementação e funcionamentos da Escola em parceria com a empresa Google. Esses achados nos proporcionaram uma Análise Descritiva a partir de três categorias: Políticas Públicas Educacionais; Corporação e Tecnologia Digital.

\section{5 análise e discussão dos resultados}

Os dados nos revelaram, inicialmente pelo site, a exiguidade de transparência na parceria entre Secretária Municipal da Educação de Salvador (SMED) e a empresa Google. Não identificamos documentos disponíveis para a sociedade realizar consultas acerca das políticas de implementação, uso e privacidade de dados dos professores e alunos. Essa inexistência contraria o artigo $5^{\circ}$, inciso XXXIII, da Constituição Federal/88 e a Lei n. ${ }^{\circ}$ 12.527/2011, que dispõem acerca do direito fundamental do acesso à informação, em que todos têm direito a receber, dos órgãos públicos, informações de seu interesse particular ou coletivo.

Nesse direcionamento, identificamos, através das Entrevistas, que no ambiente escolar há carência de esclarecimentos aos educadores e gestores sobre a parceria e o funcionamento do Projeto Google for Education nas EscoLabs, nesse caso da Boca do Rio. Além do mais, a comunidade escolar desconhece sobre a política adotada pela SMED à implementação dessa proposta na Rede Pública, as quais geraram dúvidas e preocupações sobre a proteção (privacidade) de dados da comunidade escolar, sobretudo envolvendo crianças e adolescentes. Ou seja, evidenciamos que é fundamental a participação e envolvimento da comunidade escolar na adoção de programas ou projetos para a escola, em diálogo permanente com a comunidade interna e externa.

A privação dos educadores na definição das políticas públicas educacionais tem como pretensão torná-los meros executores de "pacotes prontos" ou de iniciativas, como esta da Google, verticalizadas. Para Pretto e Bonilla (2000), Hetkowski e Dias (2019), esse cenário se repete por muitas décadas, mas afirmam que esse sistema precisa ser repensado e enfrentado, coletivamente, mobilizando e conscientizando a comunidade escolar acerca dos problemas gerados pelas multinacionais e pelas megacorporações, em especial àquelas empresas de TI.

A atuação das grandes empresas no trâmite das políticas públicas, consequentemente, interfere na formação dos professores. Na EscoLab, o "Grupo Santillana ${ }^{17 "}$ ofereceu uma formação para uso das "ferramentas" digitais aos professores da escola. Essa empresa "educacional" é fundadora e criadora do pacote Smartlab (plataforma integradora de conteúdos

\footnotetext{
${ }^{17}$ O grupo Santillana é uma empresa educacional que atua em diversos países da Europa, América do Sul e América Central, fornece formação continuada para professores, dentre elas ensina a usar as ferramentas do Google e Microsoft, pois são parceiras dessas corporações de TI.
} 
para uso na escola) que "ensina" os docentes a utilizarem as ferramentas do Google e Microsoft, ambas corporações parcerias de TI.

Nesse cenário, a formação dos professores, na EscoLab, foi promovida pelo Grupo Santillana e focada na utilização do SmartLab. Mas de acordo com as Entrevistas a proposta foi inviável para o ambiente escolar, pois “[...] com o tempo a gente foi percebendo que isso não se adequava à realidade e a gente não fez a utilização [dessas ferramentas]”. (CAETANO).

Outro entrevistado, afirma que “[...] teve uma formação inicial e depois a gente se fechou um pouco do processo porquê...não tinha aplicabilidade e aí fizeram outras formações, mas ficou inviável de usar de qualquer jeito, porque não se aplicava ao nosso público, a nossa realidade aqui na escola". (GILBERTO).

Fica evidenciado que uma das consequências, dessas propostas, em não integrar os educadores como atores dessas políticas públicas educacionais, é a inviabilidade na efetivação dos programas e projetos, os quais não se adequam a realidade escolar. Mesmo assim, os relatos denunciam que educadores e alunos continuam submetidos a modelos "de cima para baixo", excluindo-os da participação nas decisões que atendam às demandas locais e as singularidades dos sujeitos em formação.

A falta de diálogo da SMED com a comunidade local e a negligência pela particularidade escolar, seguiu a tendência das políticas homogeneizadoras, impondo à comunidade escolar, como periferia do centro, propostas prontas e verticalizadoras. Para Boneti (2012), esses grupos sociais são ignorados na sua diferença e perspectivados à homogeneização.

Nesse sentido, embora o Grupo Santillana também tenha parceria com o Google, em Entrevistas com professores e gestores, a formação promovida por este "Grupo" empresarial foi direcionada à utilização da plataforma SmartLab e, a demanda de formações internas, da EscoLab, partiu dos próprios gestores para utilização do Google for Education. De modo que, as iniciativas da comunidade escolar potencializaram o uso dessas ferramentas na escola e, consequentemente, a efetivação da parceria "corporativa” com a Rede Pública.

Nesta pesquisa, identificamos que de nove professores entrevistados, apenas dois utilizam os serviços do Google for Education para atividades com os alunos. Também observamos que o uso das ferramentas Google servia como repositório de conteúdos, isso fez com que um professor optasse por não utilizar, afirmando que "diante do que eu tava trabalhando, na época, eu vi que não ia ser tão produtivo pra minha aula porque pra mim não faz sentido a gente utilizar o Google Sala de Aula só como repositório" (CAETANO). 
Ressaltamos que os serviços do Google são, massivamente, utilizados pela sociedade e, corroboramos com Cruz (2018), quando aponta sobre a necessidade de discussões mais aprofundadas sobre a importância de as crianças compreenderem o que é Google, o que são dados pessoais e como funciona o mercado desses dados, ou seja, sua privacidade.

Nas observações, também verificamos que, por questões operacionais, dois professores informaram não utilizar o Google for Education nos processos educativos. Uma dessas questões está relacionada a logística da escola, com o fluxo de entrada e saída de alunos ao longo do ano, bem como na dificuldade em lograr um e-mail institucional aos mesmos e a necessidade de um tablet para cada estudante.

Outros três docentes, recém-chegados na escola, informaram que nunca utilizaram o Google for Education nos processos educativos. Esses professores trabalham com atividades recreativas e lúdicas, que envolvem movimento corporal e afirmaram que essas aulas demandam atividades com outros procedimentos, além do uso das tecnologias Google.

Contudo, a EscoLab dispõe de uma boa conexão com a internet e uma quantidade aceitável de tablet para os alunos, recursos estes que permitem que os professores potencializem o uso das tecnologias digitais nas suas práticas “instituintes", não associadas as ferramentas do Google, mas como possibilidades tecnológicas criadoras.

[...] em relação a tecnologia...a gente tenta ao máximo ouvir dos alunos também, tentar se manter atualizado é difícil né, mas a gente tenta...e pensar fora da caixinha também, a gente nunca vai pensar um planejamento de uma aula muito tradicional porque não vai funcionar. (GILBERTO).

[...] eu trabalho com as tecnologias digitais, justamente com os dispositivos móveis que é o que a gente tem acesso aqui...os meninos também, muito da ideia de produção de conteúdo de maneira mais colaborativa, então a gente trabalha com produção de vídeo, edição de vídeo, produção de pequenos textos, edição, então por exemplo, no primeiro ciclo eu trabalhei muito com pesquisa na internet, sistematização das informações. No segundo a gente produziu documentário que a gente utilizou muito pra gravação, usou um aplicativo pra edição de vídeo que gerou todo o Mini Doc... então penso nessa perspectiva mesmo de produzir conteúdo de maneira colaborativa algo que eu produzo, edito, compartilho. (CAETANO).

Corroboramos os docentes sobre as possibilidades de produção, edição e compartilhamentos de conteúdos e conhecimentos de forma colaborativa, entre alunos e professores. $\mathrm{Na}$ escola, foi observado a produção de documentário, livro digital, utilizando o smartphone, tablet e internet. Entretanto, salientamos a dinâmica ambivalente da cultura digital, por um lado temos as potencialidades dos processos de aprendizagem dos estudantes a partir de experiências colaborativas, de criação e autoria, por outro, os riscos quanto ao uso das plataformas digitais big tech, devido à vulnerabilidade da privacidade dos dados de estudantes e educadores 
A partir das falas e das observações, percebemos que os docentes potencializaram o ensino e aprendizagem com o uso dessas tecnologias digitais, isso ocorreu através de pesquisas feita com os alunos, criação de documentários, práticas aliadas às tecnologias digitais e tecnologias convencionais, como os livros de literatura infanto-juvenil. Por outro lado, nota-se a necessidade de formações conceituais sobre o atual momento da cultura digital e da compreensão do contexto tecnológico, em que também devem ser discutidos os riscos e desafios gerados pela plataformização da educação, dataficação e performatividade algorítmica.

Apesar de poucos professores terem utilizado os serviços corporativos nos processos educativos, a gestão escolar informou que tratasse de uma implementação que ainda está em processo e pretende avançar no ano seguinte "a ideia é que até o final do ano todas as turmas utilizem...todas as turmas podem utilizar". (GESTOR 2).

Nesse sentido, o Google for Education também é utilizado para armazenar todos os documentos da instituição escolar e para interações entre docentes e gestores. Os sujeitos mencionaram as praticidades em se comunicar por esses meios, conforme fala: "do ponto de vista mais do fazer administrativo do dia a dia, nós usamos bastante a nuvem no Drive de forma geral para poder guardar todos os documentos da escola [...]”. (GESTOR 2).

Em relação à avaliação do uso das plataformas para interação com gestores, todos os docentes destacaram aspectos positivos, como: a facilidade nas informações, orientações, troca, compartilhamento de materiais e redução na circulação de papeis. Percebemos que essas falas estão ligadas às praticidades. De acordo com Parra et al (2018), o estabelecimento de uma infraestrutura tecnológica se apoio num duplo processo: Por um lado estão as praticidades do uso e por outro o ocultamento das condicionantes. Ou seja, os professores e gestores enxergam as experiências e facilidades de uso para o cotidiano que as ferramentas proporcionam. Entretanto, há a ausência de percepção sobre os efeitos políticos e sociais em adotar essas tecnologias na escola, eliminando as discussões sobre possíveis soluções alternativas.

Em suma, verificamos que a elaboração do projeto EscoLab, em parceria com o Google, foi decisão de alguns setores da SMED, suprimindo a participação da comunidade escolar. Essas conclusões foram constatadas através das Entrevistas com os sujeitos da pesquisa, com exceção de um coordenador que devido indisponibilidades de horário não declarou seu posicionamento. $\mathrm{O}$ grupo, de professores e coordenadores da escola da Boca do Rio, alegou que não acompanhou a construção da proposta, as discussões e/ou motivações da SMED e a implantação do EscoLab. De modo que, de onze sujeitos pesquisados e atuantes na escola, sete trabalharam desde o início 
da implementação do projeto e não foram consultados ou envolvidos no processo, apenas na sua finalidade.

Podemos identificar, nas Entrevistas, alguns depoimentos relativos a esta questão: “[...] era algo que foi muito tratado em nível de Gabinete mesmo [...] a circulação da informação era com os grupos específicos que estavam vinculados a implantação via Gabinete" (GESTOR 2) e, "Como já falamos anteriormente, tem o projeto que foi pensado via Gabinete na Secretaria e ele de alguma forma orientou a implantação dos três EscoLabs [...]”. (GESTOR 1).

Tais afirmativas, nos conduzem perceber que as políticas públicas, de acesso as tecnologias na escola, ainda ocorrem a partir de jogos de forças e de relações de poder ${ }^{18}$, onde as megacorporações são privilegiadas, a sociedade civil escanteada e o potencial econômico do Estado, neste caso específico, com sua máquina administrativa, delimita e condiciona ações mais convenientes a um dos agentes, neste caso da elite dominante.

\section{6 considerações finais}

Concluímos que a elaboração do projeto EscoLab envolvendo a parceria com o Google, foram decisões de poucos setores da SMED, deixando de fora a comunidade escolar, constituindo assim, uma política verticalizada em que o governo priorizou uma corporação sem atender as demandas da sociedade civil.

Reafirmamos a urgência da compreensão dos riscos sobre os serviços corporativos de tecnologia nas escolas, justamente por serem empreendimentos privados que atuam em ambientes de disputas econômicas operando na lógica da lucratividade. Em razão disso, o estudo apontou para a necessidade de políticas horizontais que dialogue com a comunidade e de formações continuadas que discutam conceitos acerca do novo cenário da cultura digital que envolvem a plataformização, dataficação e performatividade algorítmica, capitalismo da vigilância e sobre os monopólios das corporações de TI.

Embora a pesquisa tenha proporcionado um direcionamento para a Educação Básica, as plataformas corporativas também são implementadas no ensino superior através dessas parcerias. Por isso, surge novas pesquisas que discutam os impactos sociais, políticos e pedagógicos que essas empresas de TI podem gerar no cenário educacional.

\footnotetext{
${ }^{18}$ Boneti (2006) elucida os três agentes definidores das políticas públicas: elites internacionais que exercem uma correção de forças no plano global; organizações da sociedade civil e os movimentos sociais que apresentam múltiplas formas e dentro de uma trama histórica, ressurgente, contra hegemônico (plano local) e; o Estado como grande interventor, mediador, repassador à sociedade civil das decisões geradas no âmbito das correlações de forças (plano nacional).
} 


\section{Referências}

BRASIL. Lei no 8.069, Estatuto da Criança e do Adolescente. Brasília: Diário Oficial da União, 1990. BRASIL.

BONETI, Lindomar Wessler. Políticas Públicas por dentro. Ijuí: Unijuí, 2006.

BONETI, Lindomar Wessler. As politicas públicas no contexto do capitalismo globalizado: da razão moderna à insurgência de processos e agentes sociais novos. PRACS: Revista Eletrônica de Humanidades do Curso de Ciências Sociais da UNIFAP, Macapá, n. 5, p. 17-28, dez. 2012. < http://dx.doi.org.10.18468/pracs.

BONILLA, Maria Helena Silveira, PRETTO, Nelson. Politicas Brasileiras de Educação e informática. UFBA, $2000<$ <ttp:/ / wmw2.ufba.br/ bonilla/politicas.htm> Acesso em: 06 mai. 2019.

CRUZ, Leonardo Ribeiro da. Secretarias de Educação entregam alunos de bandeja como clientes para gigantes da tecnologia. Entrevista concedida ao Lavits. Disponível em: https://lavits.org/secretariasde-educacao-entregam-alunos-de-bandeja-como-clientes-para\%02gigantes-datecnologia/?lang=pt Acesso em 01 nov. 2020.

DIJCK, J. Van; POELL, T. Social media platforms and education. In: The SAGE Handbook of Social Media, 579-591, edited by Jean Burgess, Alice Marwick \&o Thomas Poell. London: Sage. 2018.

FRIGOTTO, Gaudêncio; CIAVATTA, Maria. Educação Básica no Brasil na década de 1990: subordinação ativa e consentida à lógica do mercado. Educação \& Sociedade. v.24 n.82. Campinas. Abril 2003.

GENTILI, Pablo. A Falsificação do Consenso. São Paulo: Vozes, 1998.

HETKOWSKI, Tânia Maria. Políticas Públicas: Tecnologias da Informação e Comunicação e Novas Práticas Pedagógicas. Bahia, Tese de Doutorado, UFBA, 2004.

HETKOWSKI, Tânia Maria; DLAS, Josemeire Machado. Educação, Cultura Digital e Espaços Formativos. Plurais Revista Multidisciplinar. Salvador, v. 4, n. 2, p. 11-25, mai./ago. 2019. https://doi.org/10.29378/plurais.2447-9373.2010.v1.n1.\%p

JUNQUEIRA, Eduardo S. Estudos de plataforma: análise de dimensões do fenômeno no campo da educação. XII Simpósio Nacional da ABCiber. UFRGS, Porto Alegre, RS, 2019.

KANASHIRO, Marta. Lavits participa de reportagem de rádio sobre acordo entre Google e Unicamp. Entrevista concedida ao WebRádio Oxigênio, 2016. Disponível em: <Lavits participa de reportagem de rádio sobre acordo entre Google e Unicamp - http://lavits.org/>Acesso em: 26 set. 2020.

LEHRER, Roberto. Da Ideologia do Desenvolvimento à Ideologia da Globalizạạão: a educação como estratégia do Banco Mundial para o "alivio da pobreza". São Paulo, USP, 1998.

LEMOS. André. Os Desafios Atuais da Cibercultura. Disponível em: http:/ / www.lab404.ufba.br/?p=3599 Texto publicado originalmente no Caderno de Sábado do jornal Correio do Povo (15/06/19). Acesso em: 16 jan. 2020 
LEMOS, A.; MARQUES, D. Interfaces Maliciosas: estratégias de coleta de dados pessoais em aplicativos. V!RUS, São Carlos, n. 19, 2019. [online]. Disponível em:

http://www.nomads.usp.br/virus/_virus19/?sec=4\&item=2\&lang=pt>. Acesso em: 13 dez. 2019. https://doi.org/10.4237

LÉVY, P. A inteligência coletiva: por uma antropologia do ciberespaço. 4. ed. São Paulo: Loyola, 2003.

PARRA, Henrique Zoqui Martins. et al. Infraestruturas, Economia e Politica Informacional: o Caso do Google Suite For Education. Mediações - Revista de Ciências Sociais, Londrina - PR. 2018 Disponível em http://www.uel.br/revistas/uel/index.php/mediacoes/article/view/32320/pdf_1 Acesso em:10 out. 2019. http://dx.doi.org/10.5433/2176-6665.2018v23n1p63

SAAD, Elizabeth. Sociedade Digitalizada: "plataformização" das relações e uma privacidade "zerada" Jornal da USP, São Paulo, 2019. https://jornal.usp.br/artigos/sociedade-digitalizada-plataformizacaodas-relacoes-e-uma-privacidade-zerada/ > Acesso em: 29 mar. 2020

VENTURINI, JAMILA. Escolas na mirra das corporações da internet. Entrevista concedida ao Outras Palavras, 2019. <https://outraspalavras.net/tecnologiaemdisputa/escolas-na-mira-dascorporacoes-da-internet/> Acesso em: 30 mar. 2020

YIN, Robert K. Estudo de Caso: planejamento e métodos/ Robert K. Yin; $2^{\mathrm{a}}$ ed. - Porto Alegre: Bookman, 2001.

ZUBOFF, Shoshana. Big other: surveillance capitalismo and the prospects of an information civilization. Jounal of information Technology, Oxford, v.30, p.75 - 89, abr. 2015. http://doi: 10.1057 / jit. 2015.5 